\title{
ADVANCED ENGINE CONTROL POSSIBILITIES TO REACT ON FUEL FEATURES
}

\section{MARCEL ŠKAROHLÍD}

Josef Božek Research Centre of Engine and Automotive Engineering, Technická 4, 16607 Praha 6, Czech Republic, Tel.: +420 224351827, E-mail: marcel.skarohlid@fs.cvut.cz

\section{SHRNUTí \\ Tématem tohoto článku je zkoumání kombinovaného účinku změny složení zemního plynu a řizením motoru pomocí změny jednoho regulačního parametru. Za potenciální regulační parametry jsou uvažovány úhel předstihu zážehu, nastavení plnícího tlaku a poměr recirkulace výfukových plynů. Jsou zde prezentovány experimentální a simulační metody k posouzení dopadu změny složení paliva. Používané simulační nástroje byly kalibrovány pomocí experimentálních dat $\mathrm{z}$ testovaného motoru. \\ KLIĆCOV́ SLOVA: SLOŻENI PIYNNÉHO PALIVA, VÝKON, ÚČINNOST, KLEPÁNÍ, PRODUKCE ŠKODLIVIN, GT-POWER, ITERAČNÍ REGRESNÍ METODA, ÚHEL PŘEDSTIHU ZÁŽEHU, PLNÍCÍ TLAK, RECIRKULACE VÝFUKOVÝCH PLYNƯ, ŘíZENÍ MOTORU}

\section{ABSTRACT}

The main topic of this paper is investigation of the combined effect of natural gas fuel composition fluctuation and engine control intervention with regards to only one parameter at once. Ignition timing, boost pressure adjustment and EGR rate are considered as potential control parameters. They are presented by experimental and simulation methodology used in order to assess fuel impact regarding basic changes in its composition. Used simulation tools have been calibrated using experimental data from tested engines. KEY WORDS: GASEOUS FUEL COMPOSITION, POWER, EFFICIENCY, ENGINE KNOCK, PRODUCTION OF POLLUTANT, GT-POWER, ITTERATIVE REGRESSION METHOD, IGNITION TIMING, BOOST PRESSURE, EXHAUST GAS RECIRCULATION, ENGINE CONTROL

\section{INTRODUCTION}

Natural gas composition varies all across the European continent. In fact, fuel gas composition depends on the gas production field location. Due to this specificity, car manufacturers have to cope with this variable aspect of the fuel gas when developing CNG engines.

The aim of this study is to assess the combined effect of natural gas fuel composition fluctuation and engine control intervention with regards to only one parameter at once. This approach aims at assessing simple engine control strategies in order to compensate engine power deterioration when fuelled with a "poor" natural gas.

Within the first part of this study, it shows the implemented methodology used in order to assess, both experimentally and with a dedicated simulation tool, fuel impact regarding basic changes in its composition. At the same time, it points out most relevant engine parameters which are likely to modify fuel gas normal combustion inside the combustion chamber.

\section{CONTENT}

Taking into account JBRC background information and knowledge acquired during previous activity the impact of the fuel composition variation on engine parameters can be estimated preliminary. The preliminary estimation should create the starting points for more comprehensive investigative activities which are described later in this study.

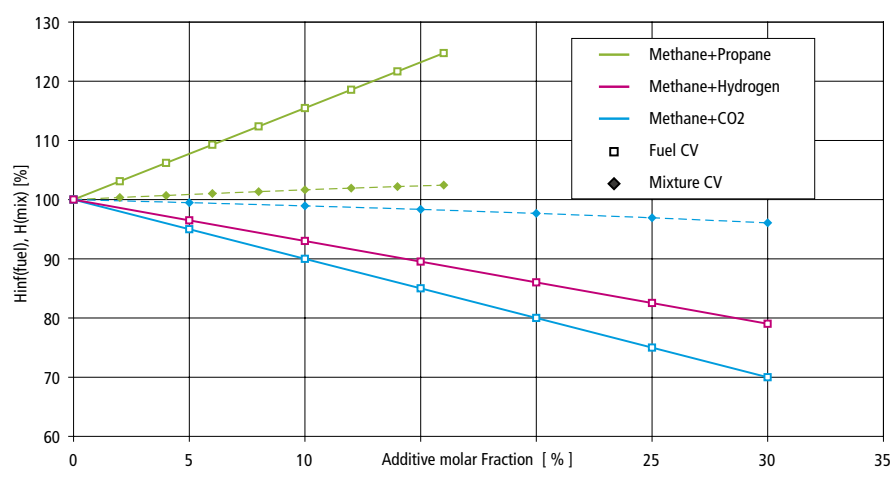

FIGURE 1: Calorific Values of Blended Fuel and Stoichiometric Mixtures OBRÁZEK 1: Výhřevnost paliva a stechiometrické směsi 
Calorific value is the main property of each fuel. Patterns of both fuel $\mathrm{CV}$ and mixture $\mathrm{CV}$ are presented in Figure 1 depending on content of $\mathrm{CO}_{2}$ (as a representative of non-combustible component), $\mathrm{C}_{3} \mathrm{H}_{8}$ (as a representative of high gaseous hydrocarbon) and $\mathrm{H}_{2}$ in a blend with pure methane. While fuel CV changes (depending on content of additive component) significantly the mixture CV changes only in order of magnitude of unit of percent. Taking into account presumed restriction of additive content (dew point at storage conditions in case of $\mathrm{CO}_{2}$ and higher hydrocarbons, accessibility of additive itself in case of $\mathrm{H}_{2}$ and higher hydrocarbons) it can be assumed that under real conditions the mixture $\mathrm{CV}$ will change in order of magnitude of fraction of percent. The variation of fuel composition affect mainly on-board capacity for energy storage and therefore vehicle range (and dimensioning of the fuel line) while effect on engine power is expected to be less significant. Nevertheless even subtle impacts will be worthy to be treated especially if advanced control systems offer sufficient possibilities to do it.

The real conditions by combustion of fuel blend containing $\mathrm{CO}_{2}$ are illustrated in Figure 2. The curves were measured at low speed, fully open throttle, $\lambda=1$, with no EGR and with boost pressure control in position giving the highest obtainable boost pressure. The worsening of engine efficiency with increased content of $\mathrm{CO}_{2}$ in the fuel blend calls for treatment. Moreover due to the deterioration of the engine efficiency the power decrease is stronger than can be derived from evaluation of mixture $\mathrm{CV}$ as presented in Figure 1.

Then the deterioration of engine power and/or efficiency is one of potential negative impact associated with presence of an undesirable component in the fuel blend. It can not be derived by simple judgment of tabulated fuel properties. In the presented example the deterioration of engine efficiency is caused by low burning velocity of $\mathrm{CO}_{2}$ - containing fuel blend. At the same time the exhaust temperature rises, which can be dangerous in the case when the temperature at turbine inlet is just at the limit of acceptability when the engine operates on original fuel (which is not the case of the mentioned example). Anyway, increased

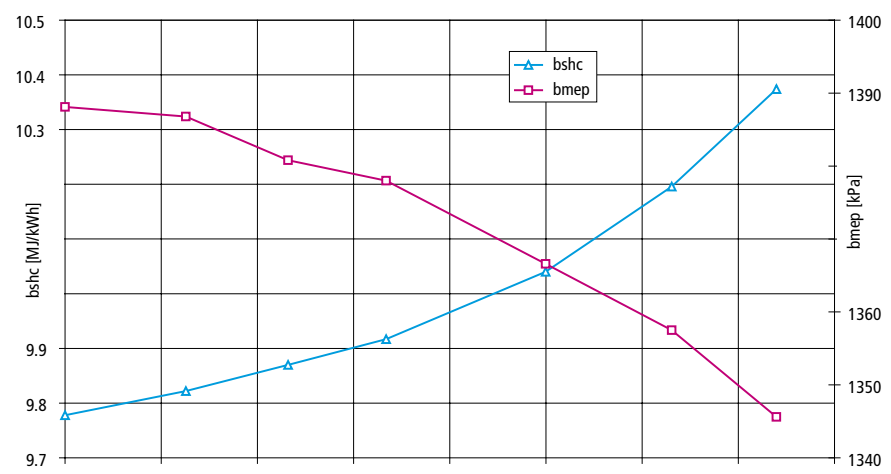

FIGURE 2: Experimentally Determined Impact of $\mathrm{CO}_{2}$ Content in Blend with TNG OBRÁZEK 2: Experimentálně stanovený vliv obsahu $\mathrm{CO}_{2}$ ve směsi s TNG exhaust temperature increases the turbine power which in turn increases both the turbocharger speed and the boost pressure. The increased boost pressure contributes to compensate power loss (in mentioned example this positive effect is still insufficient) however, on the other hand, in certain cases the turbocharger can be endangered by overspeeding (not in mentioned example). In subsequent text, the expected impacts of variation of fuel composition will be listed systematically in order to outline the scope of detailed investigation of the phenomenon.

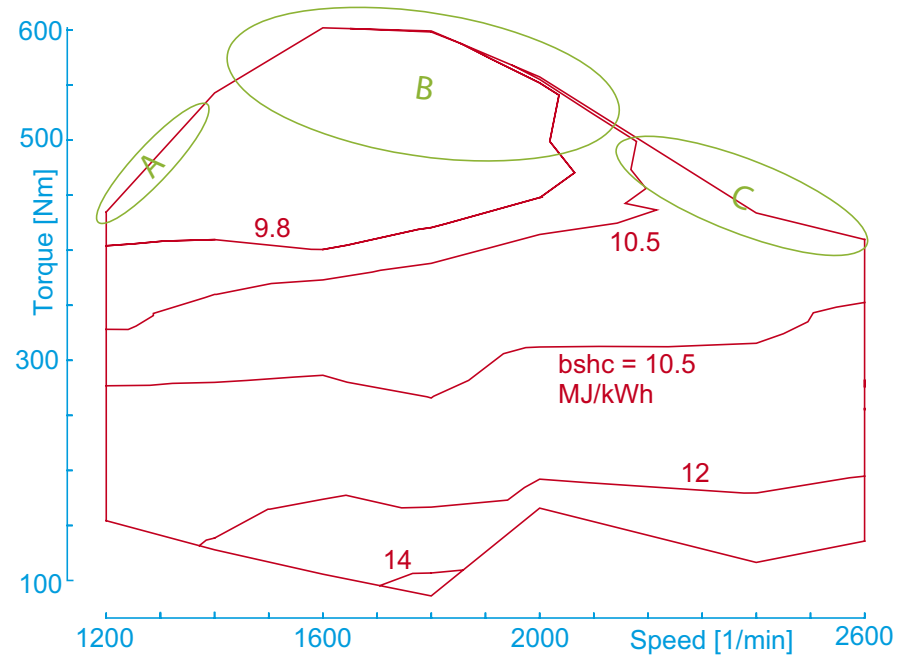

FIGURE 3: Typical Operational Areas in bshc Map OBRÁZEK 3: Typické provozní oblasti v mapě bshc

In Figure 3 an example of bsfc map is introduced (it originates from experimental activities focused to obtain calibration data for JBRC simulation tools). Several areas of operational range are marked in this Figure. Within each of these areas specific constraints are applied (including the situation where no constraints are relevant), specific demands for control algorithms are declared and subsequently specific impacts of the variations of fuel composition can be expected. All the mentioned areas are expected to be present in most engine arrangements. Their importance (relevance), varies according to the particular engine design features.

In area "A" the turbocharger does not generate sufficient boost pressure. The adjustment of all controls is focussed to obtain as high torque as possible in order to achieve sufficient torqueflexibility. EGR duct is fully closed, boost pressure control actuator touch its "MAX" stop (either physical or virtual) and ignition timing is perhaps retarded in order to enhance turbine power by increasing exhaust temperature. If a weak gaseous blend is used as a fuel there will be no way to restore original engine power. Appropriate adjustment of the ignition timing can help to minimize power loss. If a fuel blend with higher mixture $\mathrm{CV}$ is used the engine power will increase on itself. If necessary the original power output can be obtained by restriction of boost pressure. In 
each case it has to be taken into account that better fuel (with higher mixture CV compared to that for which the engine was optimized originally) shifts the border between areas " $A$ " and "B" towards lower speed.

In area "B" the boost pressure control has to keep turbocharger speed below an acceptable limit and restrict the boost pressure itself in order to protect the engine against damage by excessive peak value of in-cylinder pressure. The main engine part has to be protected against excessive thermal load by adjustment of an appropriate EGR rate. Ignition timing has to be set to achieve optimum engine efficiency especially taking into account adjusted EGR rate. If weaker fuel is used it will be possible to restore the engine power (and efficiency) by combination of EGR rate restriction, boost pressure control settings and selection of appropriate ignition timing. If fuel with higher mixture CV is used the above mentioned constraints will be highlighted and controls have to react correspondingly.

In area " $C$ " the same constraints have to be implemented as those described in comment to the area "B". Most of them are even stronger. In addition the limit of exhaust temperature at turbine inlet has to be regarded. The impact of variability of fuel composition can be judged similarly to "B" area, too.

The above mentioned description assumes knock free operation. In fact the knock danger has to be regarded (typically in the areas " $B$ " and " $C$ ") even if the engine is fueled by methane-based fuel with high knock resistance. The knock treatment is more stressed as soon as fuel with low knock resistance is used. It can be assumed that the engine will work in the region of full load curve just on knock border (at least at medium and high speed). Therefore worsening of knock resistance of the fuel blend can cause deterioration of both engine power and efficiency. Selection of appropriate set points of EGR rate and ignition timing offer certain maneuvering space for minimizing the power loss. It has to be distinguished between the situations when low knock resistance is associated with increased mixture CV (high content of high gaseous hydrocarbons) and when the mixture CV falls down simultaneously with decrease of knock resistance (blends with high content of hydrogen). In any case the knock resistance of the fuel blend is one of the main fuel properties which have to be regarded when engine is optimized for operation with fuels of various compositions.

In most operational points (those outside the "A", "B" and " $C$ ") no constraints are applied and the power itself is not an optimization criterion. Engine efficiency is the main (rather only), topic of optimization. Variations of burning velocity which is caused by variation of fuel composition create demand for tailoring the ignition timing according to the combustion characteristic of any particular fuel blend.

\section{EXPERIMENTAL EQUIPMENT}

Experimental data which were used during preparation of the present study (either directly or as a support of simulation activities) were acquired from a $4 \times \varnothing 102 / 120$ engine. This tested engine is of the size of the engines typically dedicated as a prime mover of $L D$ trucks. The engine accessory layout and its initial adjustment are arranged aiming to obtain the range and the assortment of experimental data enabling to describe impact of fuel composition in sufficiently comprehensive way. The parameters of the engine are briefly summarized in the Table 1.

\begin{tabular}{|c|c|}
\hline Engine Notation & $4 \times \varnothing 102 / 120$ \\
\hline \multicolumn{2}{|l|}{ Basic Engine Geometry } \\
\hline Cylinder \# & 4 \\
\hline Bore & $102 \mathrm{~mm}$ \\
\hline Stroke & $120 \mathrm{~mm}$ \\
\hline Displacement & $3.92 \mathrm{dm}^{3}$ \\
\hline Compression Ratio & 12 \\
\hline Valve \# / Cylinder & 4 \\
\hline \multicolumn{2}{|l|}{ Engine Performances } \\
\hline Maximum Speed & $2800 \mathrm{~min}^{-1}$ \\
\hline Maximum Torque & $\begin{array}{l}600 \mathrm{Nm} \\
@ 1500-1600 \mathrm{~min}^{-1}\end{array}$ \\
\hline Maximum Power & $\begin{array}{l}125 \mathrm{~kW} \\
@ 2400-2800 \mathrm{~min}^{-1}\end{array}$ \\
\hline \multicolumn{2}{|l|}{ Turbocharger } \\
\hline Make & CZ C12 \\
\hline Control & Variable Turbine Geometry \\
\hline Maximum Boost Pressure & $2.4 \mathrm{bar}$ \\
\hline Intercooler & Air-to-Water \\
\hline \multicolumn{2}{|l|}{ Mixture Formation } \\
\hline Arrangement & Common (central) mixer \\
\hline Excess-Air Ratio & $\lambda=1$ \\
\hline Excess-Air Ratio Control & Manual (any value) or Closed Loop $(\lambda=1)$ \\
\hline Exhaust Gas Recirculation & Cooled; Low Pressure \\
\hline Control units & \\
\hline
\end{tabular}

Distributed, Independent: $\lambda$-control;

Electronic Control Unit Ignition Control; Mixture Throttle Control; VTG Rack Control; EGR Throttle Control

TABLE 1: Description of tested engine

TABULKA 1: Popis testovaného motoru 
Pressures and temperatures of the working substance were measured in various parts of engine manifolds. The following parameters were also sensed and recorded: flows of fuels(s) and air, cooling water temperature in both engine and EGR cooling systems, engine speed and torque. Moreover, feedback messages from all actuators (mixture throttle, EGR control valve, fuel metering orifice, ignition timing adjustment and VTG rack position) were also acquired. Exhaust gas composition was determined using a conventional set of gas analyzers. An additional set of gas analyzers took samples from the engine intake manifold. The analysis outputs were used as computational inputs for determination of EGR rate and/or for verification of the composition of fuel blend. During the whole experimental run the angle-resolved patterns of in-cylinder pressures as well as the absolute pressures in both the intake and the exhaust manifold (sensors installed as close to the cylinder as possible) were acquired. Simultaneously with the records of angleresolved fast-changing pressures patterns the instantaneous crankshaft speed was measured in order to determine cylinderto-cylinder variation and verify the representatives of "single cylinder" pressure patterns from the point of view of description of behaviour of the whole engine.

Knock occurrence and intensity was monitored by AKR device. This device elaborates signal from a quite conventional vibration sensor (so called knock sensor) by discrete Fourier transform implemented in Digital Signal Processor (DSP) HW platform. It generates an analog output signal which is dedicated for ignition timing control. In test bench arrangement this AKR output was only sensed by data acquisition system. Knock intensity was recorded in this manner including the time-depending course of the (well-known), self-exciting nature of the knock phenomena when the knock was not suppressed by correction of ignition timing.

Two additional gaseous components can be delivered during engine run directly into engine intake manifold upstream of the compressor simultaneously with the delivery of main gaseous fuel. In this way the composition of fuel blend can be adjusted in a certain range and even changed while engine was running continuously.

Transit natural Gas (TNG) was used as a basic fuel. The pressure $101325 \mathrm{~Pa}$ and the temperature $273,15 \mathrm{~K}$ are considered to be normal conditions. Where relevant the properties of gaseous components were transferred from [1].

\section{SIMULATION TOOLS}

Three various simulation tools were used to model engine behaviour during the activities whose results are presented in the study. All models were created in GT-Power simulation environment.
Conventional TPA [2] procedure uses the experimentally acquired pressure patterns in the intake and the exhaust duct as border conditions. The acquired in-cylinder pressure patterns are used for determination of HR patterns by GT-Power in-build inverse algorithm. Then the in-cylinder pressure patterns are generated by forward simulation.

Modified TPA (subsequently called 2PA) also uses the manifold pressures as boundary conditions. Unlike the conventional TPA the HR patterns are determined by user routine. In this way the simulation results were generated whose comparison with experimental data is not influenced by (in)correctness or (in)accuracy of model description of engine peripheries. Compared to the use of the whole engine model (see later) the 2PA works significantly faster not being burdened by reaching the equilibrium state of turbocharger. On the other hand 2PA doesn't make it possible to predict engine parameters (e.g. depending on the fuel composition) just on account of absent important engine peripheries.

The whole engine model contains complete geometry of engine peripherals and accessories (transferred into model from reality), a complete set of correction coefficient and complete turbine and compressor maps. Definition of operating conditions is imposed as a set of inputs expressed either in terms of set points positions or as a physical value of particular quantity. The set of outputs (containing both integral quantities and angle resolved patterns - formatted according to the user demand), is generated by forward simulation running in iterative mode till the convergence conditions are reached.

The conventional TPA procedure (Figure 4) has been considered to be part of evaluation of the experimentally acquired data. The TPA then:

- Transferred the entire data structures into model environment

- Smoothed the acquired patterns by removing the impact of both electromagnetic incompatibility and disturbances caused by intrusion of acceleration-excited sensor response (especially oscillation of output voltage after intake valve hit the seat).

- Corrected any inaccuracy in determination of integral values

- Determined both the patterns and integral quantities which are not accessible for direct measurement especially zone temperatures patterns, burnt fuel fraction patterns (if desirable) and residual gas content

- Ensured reciprocal compatibility of various parts of data structure

The conventional TPA model (and its experimental counterpart in a $4 \times \varnothing 120 / 120$ engine -2 absolute pressure sensors in the intake manifold branches and absolute pressure sensor in the exhaust manifold just downstream of the cylinder outlet) was 


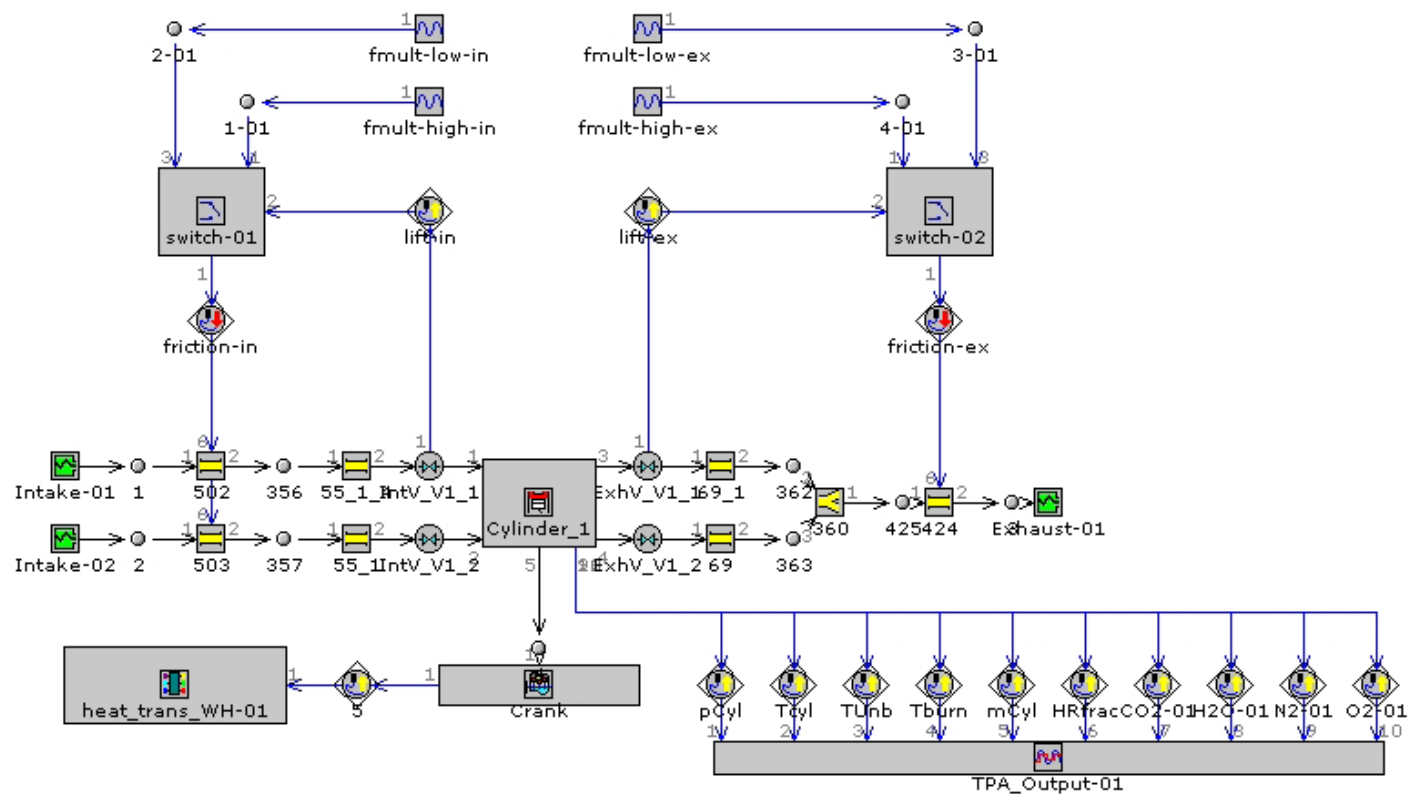

FIGURE 4: TPA Model Layout

OBRÁZEK 4: Uspořádání modelu TPA

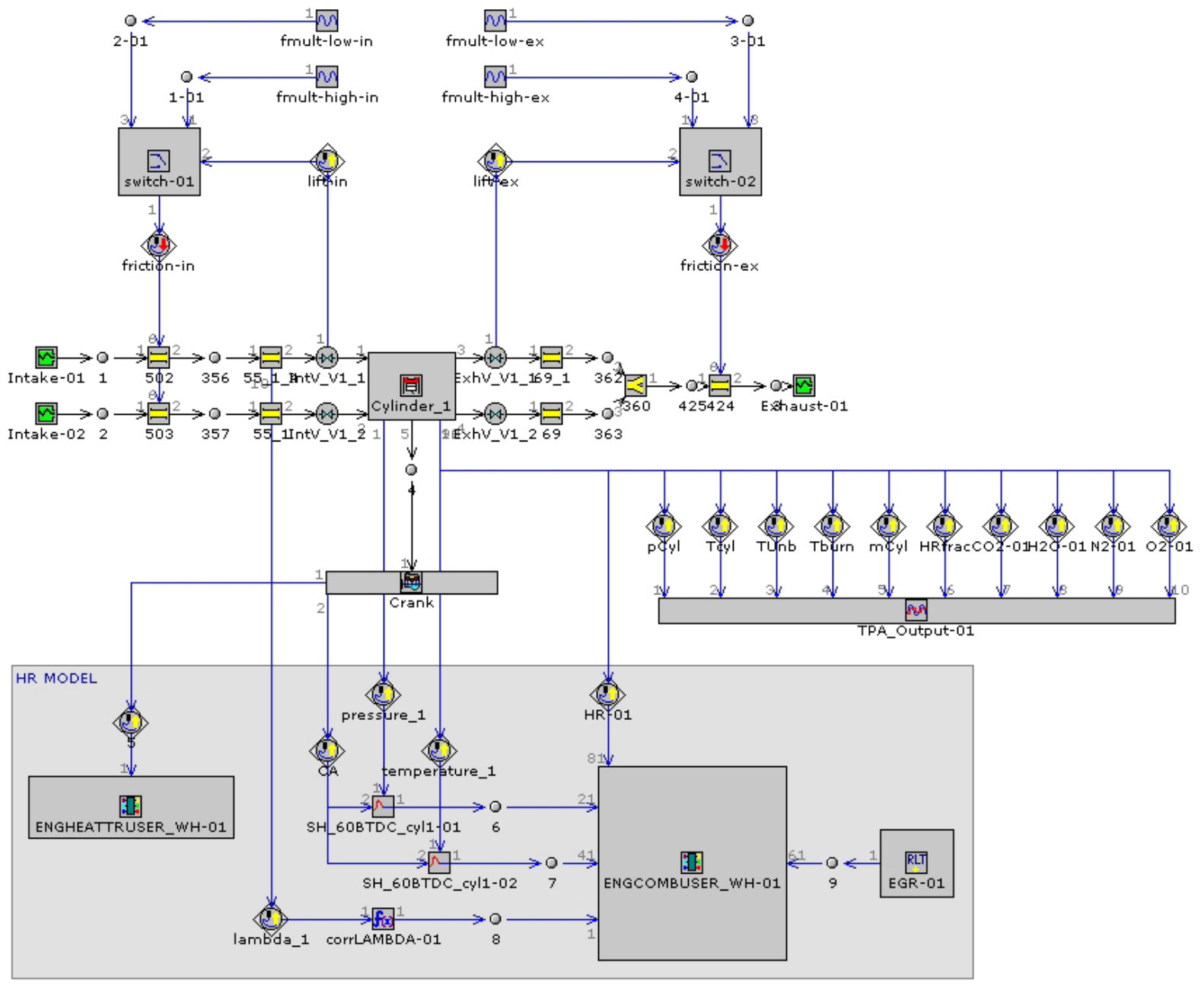

FIGURE 5: 2PA Model Layout

OBRÁZEK 5: Uspořádání modelu 2PA 


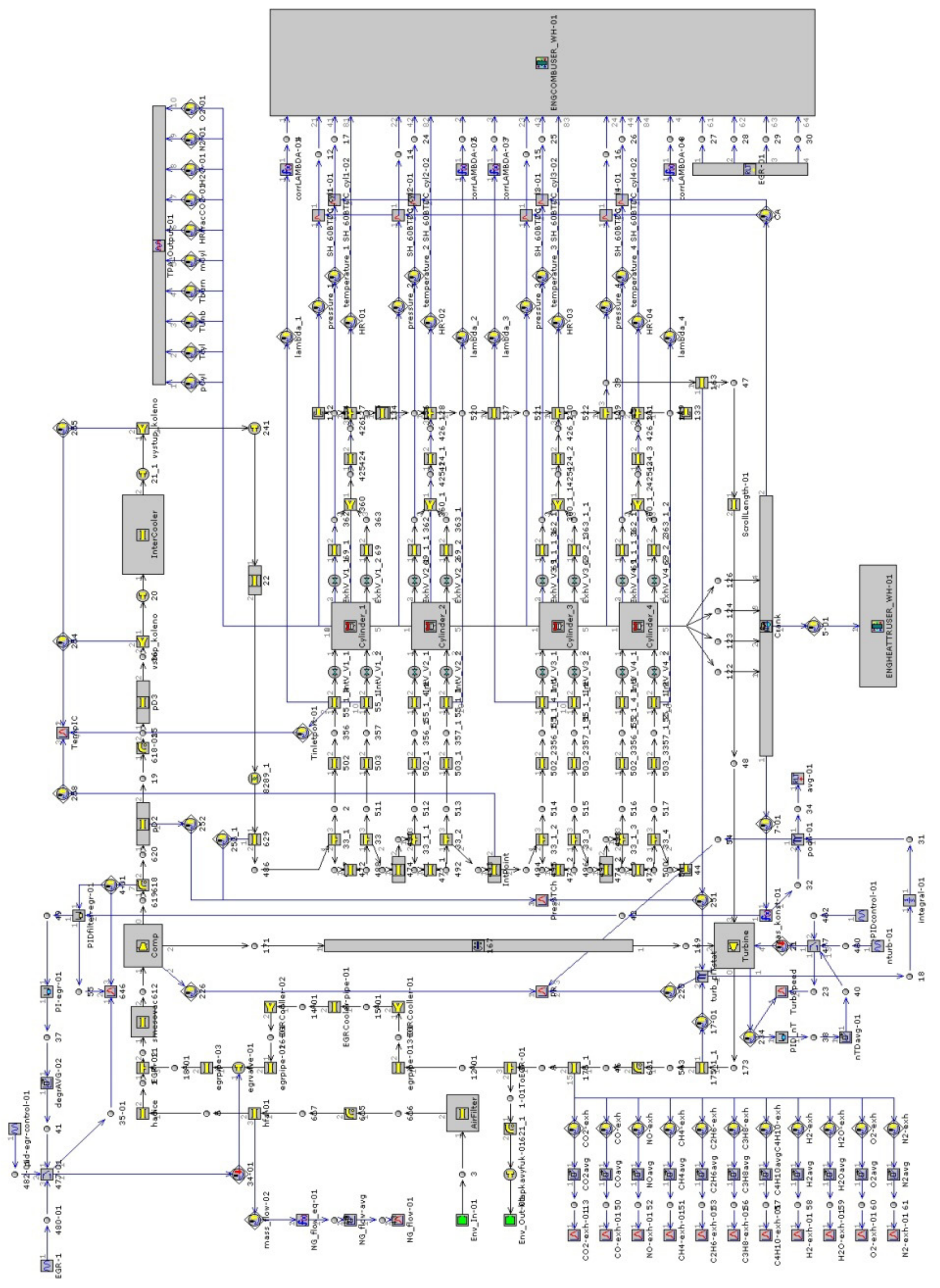

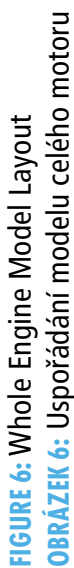


created as a part of effort dedicated to acquiring the knowledge presented in this study.

The 2PA procedure (Figure 5) was primarily used for verification of the correctness of recalculation routine for generating HR patterns which was one of the main targets of the effort whose results are described in the study. Accordance of TPA and 2PA calculation outputs is used as an evidence of plausibility of routine for generation of HR pattern (see later). Complete 2PA (including compilation its basic strategy) was created as a unique simulation tool dedicated for generation of knowledge presented in this study.

The whole engine model (Figure 6) was used primarily for generation of description of engine behaviour under various conditions by purely simulation manner. The matrices of model outputs indexed according to the values of particular components of simulation inputs should serve as a comprehensive and systematic description of influence of fuel composition, operating conditions and controls adjustments. The whole engine model contains complete geometry of engine peripherals and accessories (transferred into model from reality), a complete set of correction coefficients and complete turbine and compressor maps. The steady state compressor and turbine maps were obtained from the turbocharger manufacturer $R \& D$ department. The discharge coefficient of both exhaust and intake ports were determined experimentally at steady flow test rig. Valve lift profiles were measured and imposed together with operating valve lashes correction derived from preliminary performed common evaluation of in cylinder pressure and manifold pressures within the low pressure part of working cycle. In-house routine was created for description of wall heat transfer [3]. It implements the well-known (and for SI engine well-proven) Eichelberg's formula. The most important part of the model is the introduction of a new approach for heat release patterns determination [4].

\section{HEAT RELEASE MODEL}

The predictive ability of any forward simulation of engine working cycle is crucially dependent on quality and plausibility of the determination of heat release (HR) curve. Since 2004 in JBRC the strategy of recalculation of heat release patterns is used as it was introduced in [5]. Comprehensive description and discussion of results is introduced in [6].

The implementation of the method started from reference cycle. Reference heat release pattern is then either pushed or stretched along the crank-angle coordinate. It is performed by shifting several characteristic points on HR pattern multiplying its distance from the spark discharge point by recalculation coefficient. Recalculation coefficients for each point on HR pattern are determined as a product of effect factors. Each effect factor describes one particular circumstance which influences HR scope. The set of effect factors was chosen according to the well-proven methodology introduced in $[7,8]$. The effect factors are polynomial functions of:

- Air Excess

- Engine Speed

- Ignition Timing

- Residual Gas Content (rather sum of residual gas and outer EGR)

- Pressure and Temperature at Crank Angle Position $60^{\circ}$ bTDC.

Inputs for determination of HR pattern valid for particular simulated working cycle consist of the angle-resolved description of the reference HR pattern and the set of above mentioned effect factors. Typically the set of effect factors is tailored for given design and operational features of combustion system (combustion chamber geometry and charge movement nature and intensity) while reference cycle is obtained from in-cylinder pressure record acquired in typical operational regime. Particular values of polynomial coefficients are determined by calibration. Range of validity can be restricted to certain (limited) range of operational points in order to enhance accuracy and reliability of forward simulation results. On the other hand, the universal set of input can be used to enable model extrapolation within wide range of operational condition and/or design features of combustion system. However, a generalized approach offers lower accuracy of prediction for particular cases in comparison with one noncompromisingly tuned just for the case.

The mentioned approach was compiled for use as a simulation tool for model description of behaviour of gas fueled engines. During former activities of JBRC the strategy and implementation of above mentioned procedure were successfully tested for elaboration of engine operation on different fuels in the range from TNG to gasoline assuming that reference cycle and set of effect factors are available for each fuel.

Nevertheless the above mentioned set of effect factors does not describe influence of fuel composition. Formation of the set of effect factors involving the influence of fuel composition itself is the main topic of the presented task. The extended set of polynomial coefficients was completed by coefficient depending on mass fraction of these gases: $\mathrm{CO}, \mathrm{CO}_{2^{\prime}} \mathrm{N}_{2^{\prime}} \mathrm{H}_{2^{\prime}}$ $\mathrm{C}_{2} \mathrm{H}_{6^{\prime}} \mathrm{C}_{3} \mathrm{H}_{8}$ and $\mathrm{C}_{4} \mathrm{H}_{10}$. In any case the rest of fuel gas is methane. Particular values of these coefficients were determined by calibration simultaneously with determination of polynomial coefficients for operation parameters (as they are listed in description of original state of recalculation routine).

The calibration procedure uses experimental data acquired in sufficient amount of operating points. One possible calibration strategy is to select the subarray of points containing only the 
points with (almost) the same value of all effect factors except for just one. The polynomial coefficients for this one effect factor are determined using regression procedure. The second strategy uses all acquired points for evaluation of coefficient sets for all effect factors consecutively assuming that the distribution of all other influences is "random enough".

Multi-parametric linear regression was used for individual effect factor polynomial coefficients determination. Since the effect factors are multiplied to determine the resulting angle position of significant HR points, the iterative procedure has been developed and tested: assuming the known form of all but one effect factor, this factor regression is found. Then, the procedure is repeated step by step for other factors. This method has been called "Heat Release Iterative Regression Method" $[9,10]$.

The Burned Fuel Fraction (BF) pattern is more important as input to GT-Power main procedure because the contemporary versions of GT-Power are able to respect the combustion chemistry in a better way (than previous ones), using zone models and local chemical equilibrium of combustion products. For this reason, the HR pattern is corrected to BF pattern by an appropriate correction procedure.

For generation of a universal set of effect factors the calibration data were used which originate from measurements performed on three natural gas fueled engines of various sizes, design features and operational ranges within wide range of speed and load and with various adjustments. Calibration data was acquired during experimental activities in the JBRC laboratory (as background information).

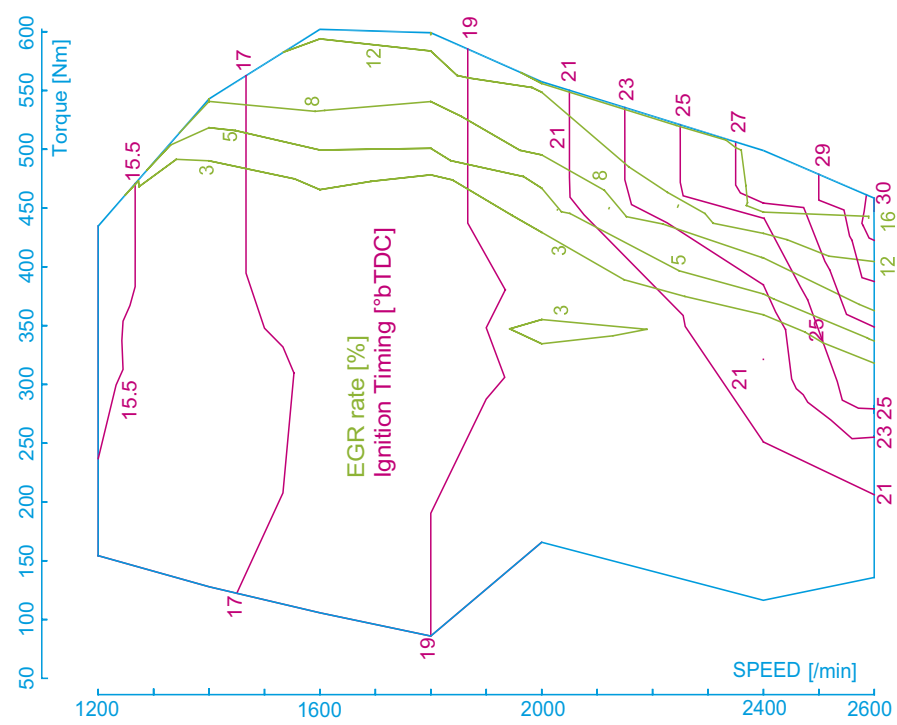

FIGURE 7: Basic Control SetPoints in Engine Map

OBRÁZEK 7: Nastavení základních rídících hodnot v charakteristice motoru
Especially for determination of effect factors depending of fuel composition a subset of calibration data was acquired purposely in sequences of consecutive operational points with stepwise increased content of relevant component in fuel blend maintaining all other control settings unchanged. The influence of addition of $\mathrm{C}_{3} \mathrm{H}_{8}$ (as a representative of high gaseous hydrocarbons), $\mathrm{CO}_{2}$ and $\mathrm{H}_{2}$ (to TNG = basic fuel) were investigated using TPA procedure. In order to express exactly the sensitivity of fuel blend of certain composition to control adjustment measurements were performed with constant (relative high) content of the above mentioned component depending on ignition timing.

The compilation of the final recalculation coefficient as a product of a particular effect factor enables simulation of both influence of fuel composition and control adjustment, and any combination of them. By multiplying the effect factors which are a function of content of individual component it is also possible to describe behaviour of the engine when fueled by blend containing several additional components. However, due to strongly nonlinear relationship determining reaction rates it is to be expected that behaviour of complex combination of several exotic components can be described by the mentioned simplified approach incorrectly.

The mentioned HR model was implemented into both the 2PA and whole engine GT models.

\section{OPERATIONAL POINT ASSORTMENT}

In Figure 7 the maps of ignition timing and EGR rate are plotted as they were determined by preliminary testing of the engine while it operated on pure TNG. The ignition timing was

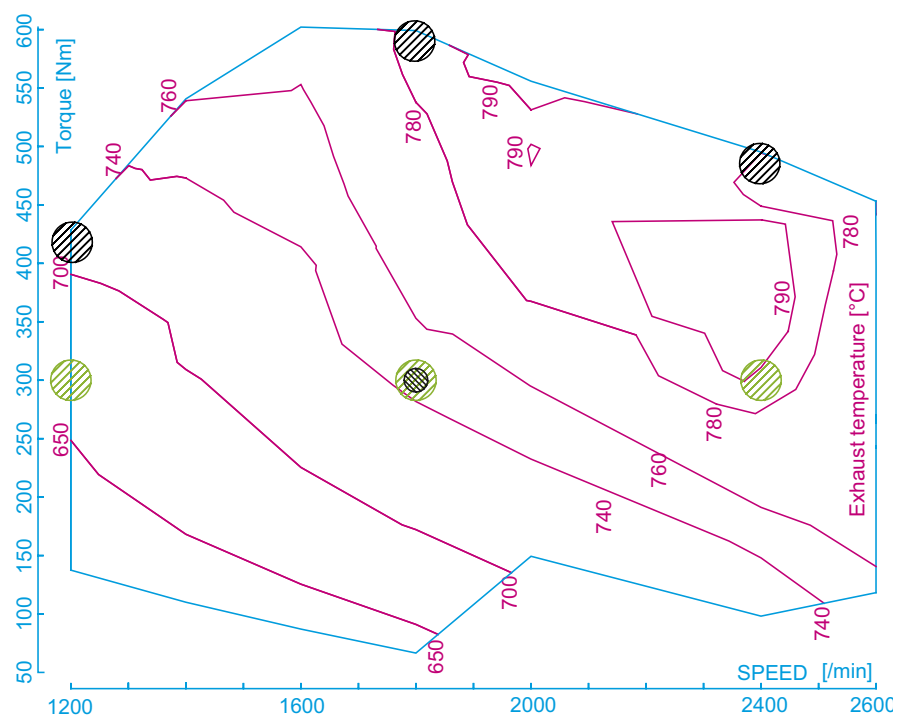

FIGURE 8: Areas of Testing of Fuel Composition Influence in Exhaust Temperature Map

OBRÁZEK 8: Oblast testování vlivu složení paliva v mapě teploty výfukových plynů 
adjusted in order to keep position of peak in-cylinder pressure at $15^{\circ}$ aTDC (with EGR control valve fully closed) in a region where no constraints took place. As soon as knock occurred (which is considered to be the main constraint) the ignition timing and EGR rate was adjusted to maintain knock-free operation trying to keep the peak pressure position still at $15^{\circ}$ aTDC. As soon as the exhaust gas temperature reached the highest acceptable value at turbine inlet $\left(800^{\circ} \mathrm{C}\right.$ for the particular turbocharger) both the ignition timing and EGR rate were adjusted in order to keep the exhaust gas temperature just at the limit (and to ensure knock-free run simultaneously) regardless of the angle position of peak in-cylinder pressure. Approximately 100 operational points were acquired within the map area. They were preprocessed by conventional TPA procedure and appended to the set of inputs for tuning of the generalized routine for recalculation of HR patterns.

In Figure 8 the exhaust temperature map is plotted as a contribution to the above mentioned explanation of adjustment strategy. In the same figure the regions are marked in which investigation of influence of fuel composition was performed. At medium load (green coloured circles in "safe" part of engine map) the sequences of operational point were acquired with stepwise increasing delivery of (always one), additional fuel component. Positions of all set-points were not changed within one sequence (kept same as during pure TNG operation). Additions of propane, carbon dioxide and hydrogen were tested. Maximum inflow of propane was limited by knock occurrence (at approx $15 \%(v o l$.$) ). During operation with addition of carbon$ dioxide (according to the expectation) knock does not occur and maximum inflow was chosen safely above $30 \%$ (vol.) significantly beyond dew point limitation at any imaginable storage condition. During operation with addition of hydrogen (surprisingly), knock also does not occur, the sequences finished as content of hydrogen in fuel blend reached approx. $25 \%$ (vol.). Similar sequences were acquired using only propane as the additive at three speeds equally distributed along full load curve (brown coloured circles in Figure 8). Of course with the set-point positions optimized for pure TNG knock occurs at significantly limited content of propane in the fuel blend (only approx. $1 \%(\mathrm{vol}$.) at $2400 \mathrm{rpm}$ ) and it was difficult to determine trends. In order to acquire experimentally the sensitivity of fuel blends to engine adjustment the sequences of operational regimes were recorded at constant flow of the aforementioned three additives at medium speed and medium load (black coloured circle in Figure 8), depending on (stepwise advanced), ignition timing. Each sequence started from a retarded position of spark discharge compared to that optimized for pure TNG operation in order to ensure sufficient manoeuvring space for subsequent shifting of spark instant towards advancing.
The aforementioned operational points (approx. 100 of them) were involved into a set of calibration data for compilation of universal HR-recalculation routine.

The compilation of routine for recalculation of HR pattern depending (among other things), on fuel composition was supported by experimental data whose records are stored in archive of JBRC laboratory. Part of them (newly recalculated and interpreted), will be involved in presentation of results in order to make the insight to the topic as complete as possible. These include especially the results of measurement performed at high load where heavy knock frequently occurs.

A set of measurements was carried out with closed-loop lambda-control switched off depending on air excess ratio in the range from $\lambda$ (slightly) $<1$ to lean limit of flammability (determined by $\mathrm{COV}_{\text {imep }}$ ). Neither acquired data nor the results of their elaboration are included in this study. They were involved into the set of calibration data for compilation of HR model and archived for further activities focused on description of behaviour of lean burn engines.

\section{EXPERIMENTAL RESULTS}

Besides the use of experimental data as calibration and verification source for simulations the acquired data themselves contain a certain amount of knowledge which is worth presenting. In Figure 9 to Figure 12 the engine behaviour at full load curve is described.

In Figure 9 and Figure 11 the ignition timing curves are plotted which should keep the engine operating just on the knock border. The curves were derived from sequences of operational regimes each acquired at constant delivery of just one fuel additive with stepwise advanced ignition timing starting from retarded ignition, ensuring knock-free operation in the initial operating regime. Acquisition of each sequence was stopped as soon as an unacceptable level of knock had been reached. The last recorded knock-free (or with occurrence of very light knock), point was selected from each sequence. The points determined in this manner create the vertices of the broken lines in Figure 9 and Figure 11.

The basic operational regimes were chosen at low speed with no EGR delivery (as a representative of area "A"), and at medium speed with fully open EGR control valve (typical for "B" area). In all cases the air excess ratio was kept stoichiometric. The mentioned data were acquired on the engine equipped with the turbocharger with WG control (bypass valve controlled directly by pressure cell without any ECU). In this arrangement higher boost pressure at low speed had been achieved than that achieved with the version with variable turbine geometry (VTG in turn shows better performance at high speed and at low load along the whole speed range). The curves of peak 
in-cylinder pressure are included in Figure 9 and Figure 11 to make insight into the topic more complete. The impact of variation of the knock resistance of particular fuel components is presented in figures Figure 10 and Figure 12. Engine power and efficiency are expressed in these figures as a percentage of the values achieved at pure TNG operation.

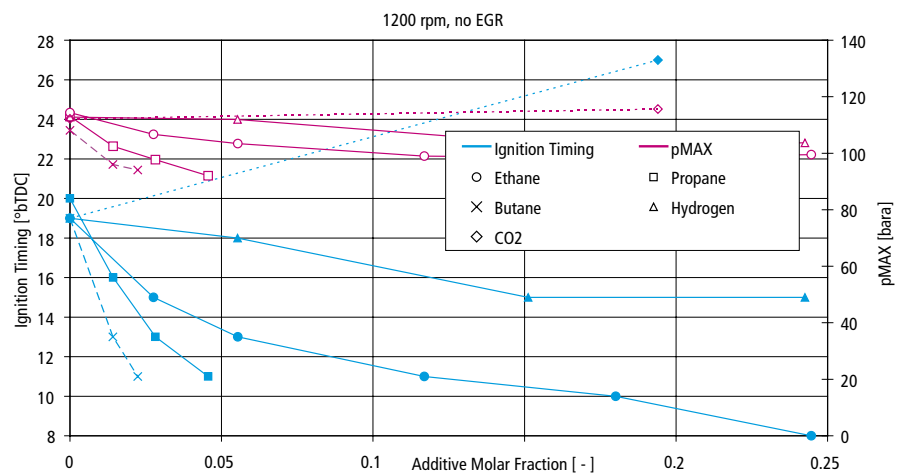

FIGURE 9: Ignition Timing and Peak Cycle Pressure at Knock Border, WOT, Low Speed

OBRÁZEK 9: Předstih zážehu a maximální tlak ve válci na hranici klepání, WOT, nízké otáčky

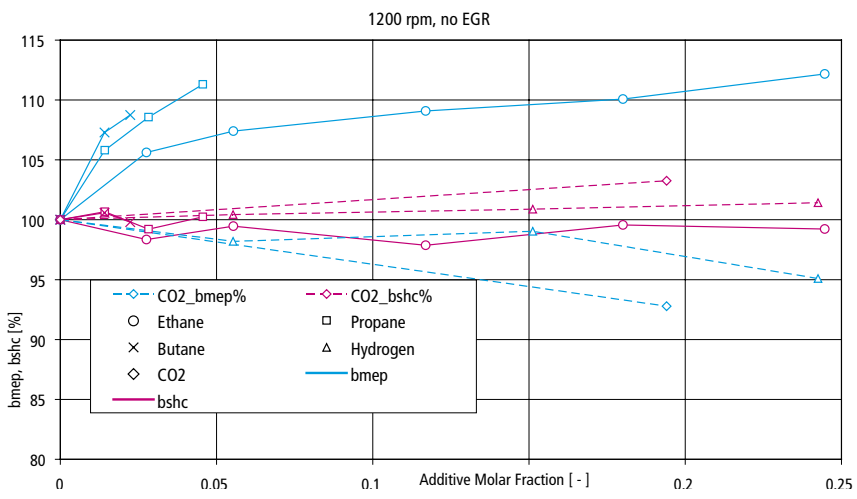

FIGURE 10: bmep and bshc at Knock Border, WOT, Low Speed OBRÁZEK 10: bmep a bshc na hranici klepání, WOT, nízké otáčky

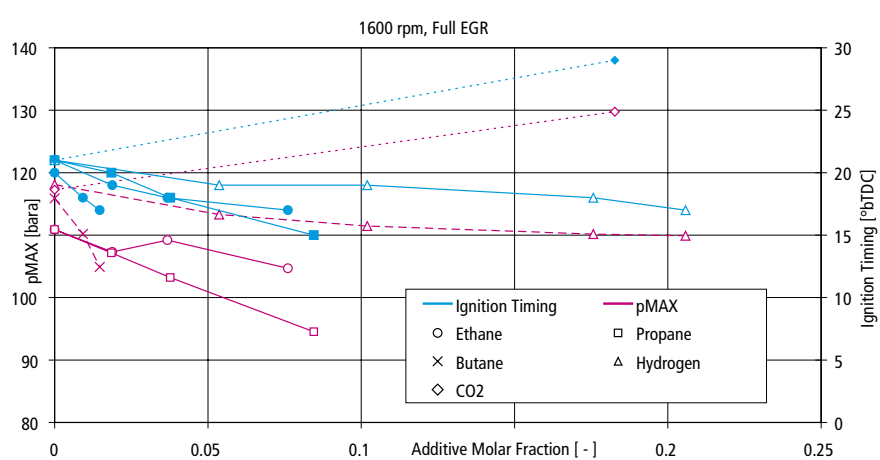

FIGURE 11: Ignition Timing and Peak Cycle Pressure at Knock Border, WOT, Medium Speed

OBRÁZEK 11: Předstih zážehu a maximální tlak ve válci na hranici klepání, WOT, střední otáčky
The basic impact of presence of the particular component in fuel blend in a situation when no constraints are applied is described in Figure 13. In this figure engine power and efficiency is plotted as a percentage of the values valid for pure TNG operation, depending on molar fractions of propane, hydrogen and carbon dioxide. Data were acquired at medium speed and load at air excess ratio $=1$ (with lambda-control active) without EGR delivery and with ignition timing as it had been found close to optimum by pure TNG fueling. The VTG rack was adjusted to the position giving the lowest boost pressure and mixture flow was throttled in order to adjust engine load as declared in Figure 8 (green coloured circles). Presented data were used as a part of a set of calibration data for simulation tools.

Exhaust gas composition is described in figure Figure 14 , depending again on molar fractions of additives. It has to be pointed out that the molar fraction of methane in exhaust (determined by NDIRA [11]), is plotted in this figure (and in all presentation of exhaust gas composition within present study), as a representative quantity concerning content of (unburned), hydrocarbons.

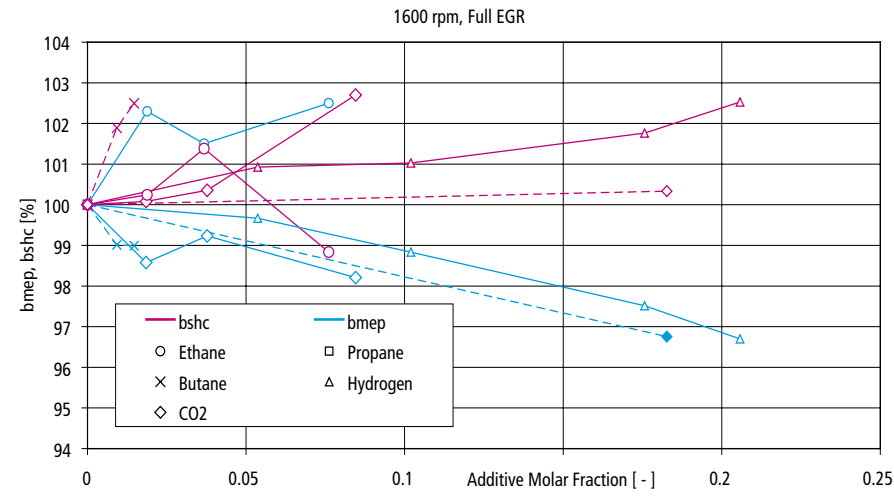

FIGURE 12: bmep and bshc at Knock Border, WOT, Medium Speed,

Controlled Boost Pressure

OBRÁZEK 12: bmep a bshc na hranici klepání, WOT, střední otáčky, řizený plnící tlak

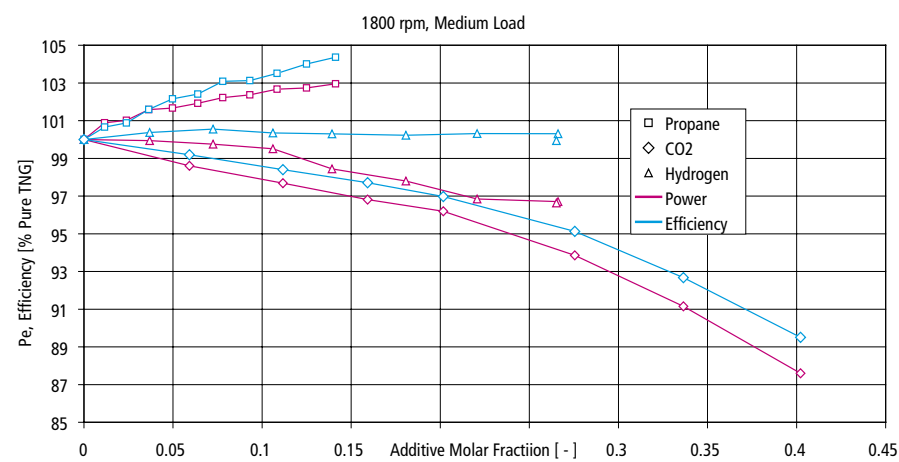

FIGURE 13: Engine Power and Efficiency with Constant Controls Adjustments

OBRÁZEK 13: Výkon a účinnost motoru při konstantním nastavením řídících prvků 


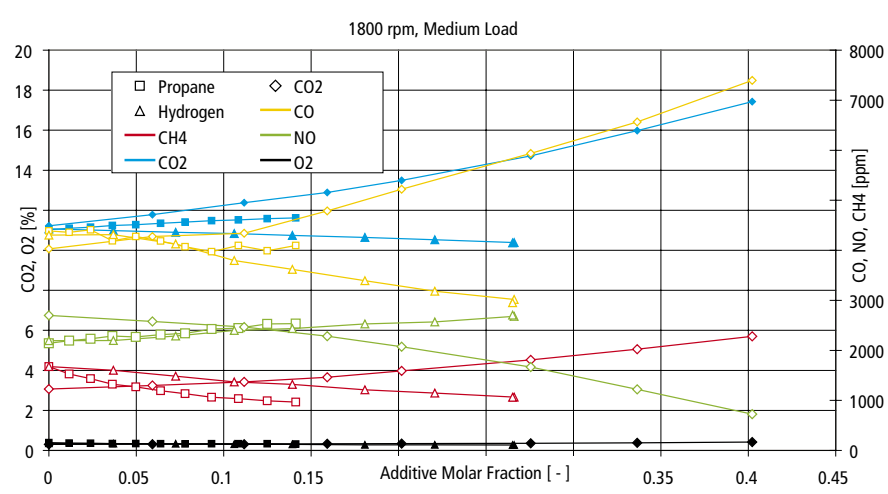

FIGURE 14: Exhaust Gas Composition

OBRÁZEK 14: Složení výfukových plynů

The experimentally acquired information about exhaust gas composition can be summarized as follows. The exhaust gas composition changes, following expected and logical trends. Content of $\mathrm{CO}_{2}$ in exhaust gas develops correspondingly to the content of carbon in fuel. Content of products of incomplete oxidization $\left(\mathrm{CO}, \mathrm{CH}_{4}\right)$, in exhaust gas rises with an increased amount of $\mathrm{CO}_{2}$ in fuel and falls with increased amount of hydrogen. With addition of propane the content of methane in exhaust gas falls (more steeply then corresponds to the decreased content of methane in fuel), whereas content of carbon monoxide in exhaust gas remains (approximately), unchanged. Content of NO in exhaust gas increases with increasing addition of both propane and hydrogen and it decreases (steeply), with an increasing amount of $\mathrm{CO}_{2}$ in fuel. All changes of raw exhaust gas composition are insignificant.

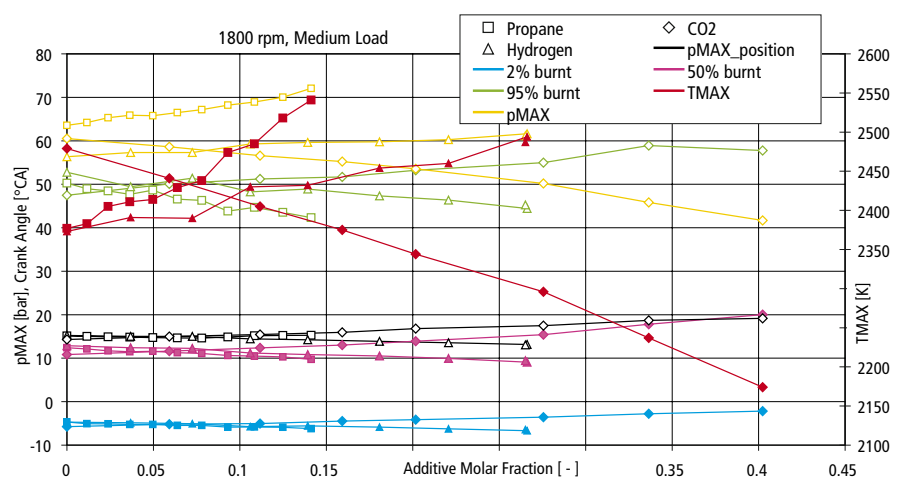

FIGURE 15: Evaluation of In-Cylinder Pressure Record OBRÁZEK 15: Vyhodnocení záznamu tlaku ve válci

The results of evaluation of acquired in-cylinder pressure patterns are presented in Figure 15. Combustion phasing is described in this figure by the plot of iso-lines of crank angle position in which the normalized HR pattern reaches the values of 2,50, and 95 percent. Angle position of peak cycle pressure is presented too. The overall view is completed by curves of peak cycle pressure and temperature.

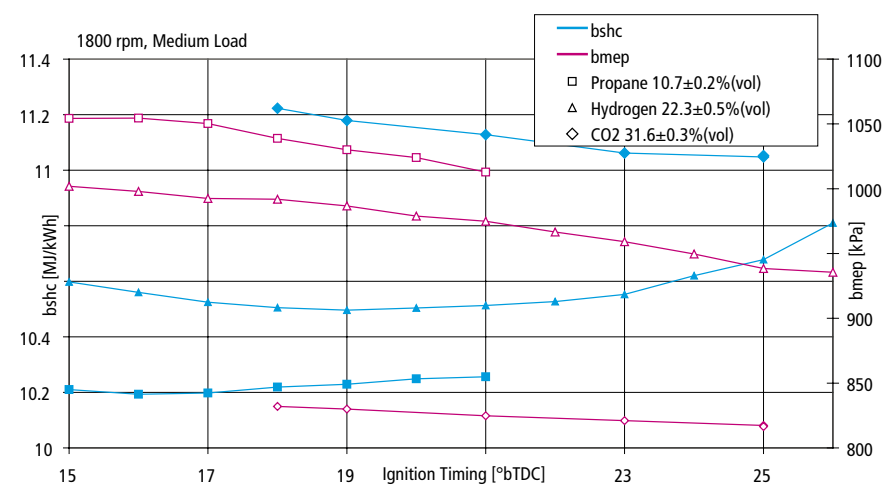

FIGURE 16: Basic Influence of Ignition Timing at Part Load OBRÁZEK 16: Základní vliv předstihu zážehu při částečném zatižení

The curves valid for use of propane and hydrogen as the additives were measured by EGR control valve in a fully closed position. Nevertheless the EGR (butterfly type), valve is not absolutely leakage-proof and in fact a very small amount of EGR was delivered into the compressor intake. During experiments with addition of $\mathrm{CO}_{2}$ the $\mathrm{EGR}$ line was completely plugged up in order to avoid distortion of results by $\mathrm{CO}_{2}$ delivered as a part of EGR. That is why the leftmost points (molar fraction of additive $=0$ ), of curves describing influence of $\mathrm{CO}_{2}$ are shifted towards higher peak in-cylinder temperature, higher molar fraction of NO and lower molar fractions of products of incomplete combustion in exhaust gas.

Insulated influence of ignition timing at engine operation when fueled by blends of various compositions is described in Figure 16. The almost constant content of additive in the fuel blend was kept along the sequence of stepwise advanced ignition timings (In fact the flow of the additive was kept constant while TNG consumption slightly changed correspondingly to the change of mixture flow depending of ignition timing adjustment). Air excess ratio was kept at a value of 1 (lambda-control active), EGR was not delivered, VTG rack was in a position giving the lowest boost pressure and mixture flow was throttled. The absolute values of engine bmep and bsfc are presented in Figure 16.

Certain partial conclusions can be derived from experimentally acquired knowledge even if they cannot be documented / illustrated by graphics.

The mixture formation on a $4 \times \varnothing 102 / 120$ testing engine is ensured by a common mixer. The $\lambda$-control actuator influences the cross sectional area of the metering orifice for fuel at the mixer inlet. When the engine is fuelled by an on-line mixed fuel blend, the $\lambda$-control actuator controls only TNG flow, while the flow of the additive changes neither in the framework of periodical fluctuation of actuator position under a steadystate condition, nor in the situation when the mean position of the actuator is shifted during transient operation. It can be assumed that this arrangement represents the "worst case 
study" as concerns the assessment of behaviour of the $\lambda$-control system itself. Nevertheless, even in this situation the deviation of $\lambda$-control system behaviour (frequency and amplitude of periodical actuator movement), were not observed when an additive was injected (compared to pure TNG fuelling). Therefore it can be assumed that a quite conventional $\lambda$-control system will work correctly with any fuel blend.

From evaluation of indicator diagrams acquired while the engine ran with occurrence of knock it was derived that the basic impact of knock phenomenon itself is very similar, dependent on the actual composition of the fuel blend. Nevertheless, certain (very subtle), differences were revealed (for now more as an individual observation than systematic). During pure TNG operation the "light knock" state was identified, when the record of consecutively acquired working cycles consisted of a great number of knock-free cycles combined with several cycles showing quite high intensity of knock (high secondary peak on Rate-of-Heat-Release curve and high amplitude of oscillation of in-cylinder pressure). During operation with the addition of propane the distribution of knock intensity along the sequence of consecutively acquired cycles was more uniform. The record contained a great number of cycles showing low intensity of knock, and knock-free cycles occured only occasionally. In both mentioned cases the AKR - knock recognition device generated the same output. As mentioned, the AKR devices perform sophisticated evaluation of instantaneous knock intensity. It also exploits its huge computational power (being based on DSP platform), for additional sophisticated evaluation of timedependent history of instantaneously evaluated knock intensity. The AKR output is always compiled from determined actual instantaneous value of knock intensity, and from the scope of the previously recorded patterns of knock intensity. The cost effective instrumentation for detection of knock as it is typically implemented in stock-produced automotive engines (such as BOSCH 0272230424 vibration sensor evaluation module), uses a simpler algorithm for knock-sensor signal evaluation (windowing - band pass - rectifying - integration). This simple algorithm (tailored for operation with certain fuel), can identify the knock intensity unequally for various fuels. It was considered that it is worth making engine designers aware of the aforementioned circumstances even if (till now), they are more subtle indications rather than doubtlessly confirmed fact.

\section{ITERATIVE REGRESSION HR MODEL ASSESSMENT}

Figure 17 offers an overview of correctness of the HR model and its usability. The directly measured patterns are compared with results of TPA and 2PA as well. It has to be pointed out that a quite universal reference cycle and a quite generalized set of recalculation coefficients were used for generation of HR pattern in 2PA. Especially the influence of operating conditions is estimated as a rough approximation. Nevertheless the directions of trends and their robustness are reflected correctly.

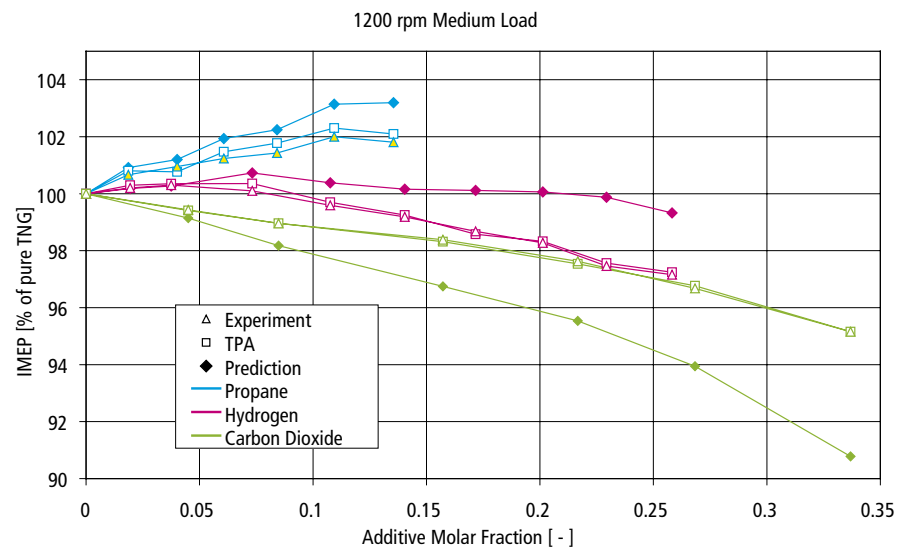

FIGURE 17: Comparison of 2PA Prediction with Experimental and TPA Results

OBRÁZEK 17: Porovnání predikce 2PA s výsledky experimentu a TPA

In the next paragraph the simulation results will be presented as they were obtained, using the whole engine model with the implemented Iterative Regression HR model as a generator of HR patterns. Matrices of description of engine parameters dependent on fuel composition and control adjustment were generated by forward simulation.

\section{DETERMINATION OF MOST RELEVANT ENGINE PARAMETERS}

Systematic description of combined impact of fuel composition and position of control elements is performed using the whole engine model containing HR model as a source of description of HR patterns. The description of behaviour of engine peripheries and accessories is generated by model in-built procedures. Thus, the matrices of results were created, every time indexed by the content of just one fuel additive, and by the position of just one control element, maintaining everything else unchanged. The matrices were created for a certain range of additive content (starting from zero), and for a certain range of set-points adjustments distributed around the presumed optimum. No constraints were taken into account, therefore part of results is extended beyond the limits which would have trimmed the operational range if the matrix had been acquired experimentally. With the highest probability it can be assumed that friction losses will not be influenced by fuel composition. That is why indicated values of mean effective pressure and efficiency were chosen for presentation of impact on engine power and efficiency. In this manner the results cannot be deteriorated by uncertainties and inaccuracies in determination of friction losses. 
The simulation results also contain a description of the development of piston temperature dependent on fuel composition and control set-points. It was chosen as a representative of "structure temperatures" which are important circumstances which have to be taken into account by tailoring the set-point adjustment (especially EGR rate), to engine operation on a particular fuel blend. The simulation results obtained with the correctly calibrated model are probably the most plausible information about structure temperatures.

To enable the assessment of mechanical strain the maximum in-cylinder pressure is calculated for each point. The calculated maps of turbocharger speed enable assessment of how the turbocharger can be endangered by over speeding. A conflict with constraints (if any), can be revealed from the maps of piston temperature, peak pressure and turbocharger speed.

Three various engine speeds were modelled. All the simulation results have one common operation regime - a basic operation regime for each engine speed. In this paper only the results for $\mathrm{CO}_{2}$ and $1800 \mathrm{rpm}$ are presented. The results for addition of propane and hydrogen and various engine speeds are processed, but, because of the scope of the article, are not listed. These results are accessible on demand in the author's (JBRC) archive. The definition of basic regimes and ranges of investigation:

Engine speed: 1200 rpm

Air excess: 1

Ignition timing: $20^{\circ} \mathrm{bTDC}$

test range: $16-24^{\circ} \mathrm{bTDC}$

Throttle: WOT

Fuel: TNG

EGR: $0 \%$

VTG rack position: 0

test range: $0-15 \%$

test range: $0-1$

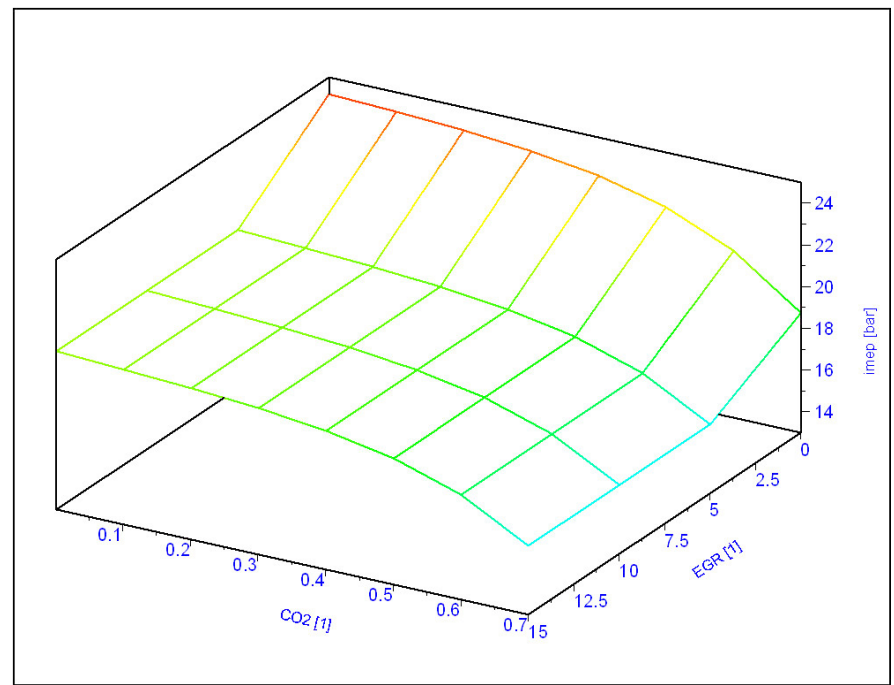

FIGURE 18: Indicated effective mean pressure map for EGR control OBRÁZEK 18: Mapa indikovaného užitečného tlaku pro řizení pomocí EGR
Engine speed: 1800 rpm

Air excess: 1

Ignition timing: $20^{\circ} \mathrm{bTDC}$

test range: $16-24^{\circ}$ bTDC

Throttle: WOT

Fuel: TNG

EGR: $10 \%$

VTG rack position: 0.5

test range: 0-15\%

test range: $0.25-1$

Engine speed: 2400 rpm

Air excess: 1

Ignition timing: $20^{\circ}$ bTDC

test range: $16-24^{\circ} \mathrm{bTDC}$

Throttle: WOT

Fuel: TNG

EGR: $15 \%$

VTG rack position: 1

test range: $0-15 \%$

test range: $0.8-1$

\subsection{EGR RATE CONTROL}

EGR rate control was simulated with the synchronous change of EGR fraction and the mass fraction of $\mathrm{C}_{3} \mathrm{H}_{8}, \mathrm{H}_{2}$ and $\mathrm{CO}_{2}$ in fuel. The change of EGR fraction was realized by the change of EGR valve diameter. The change of mass fraction of additive gases was realized by the change of fuel definition. Other parameters were constant but some of them (for example boost pressure, etc.), were influenced by the change of EGR fraction and mass fraction of additive gases.

Figure 18 shows the dependence of indicated effective mean pressure on the $\mathrm{CO}_{2}$ mass fraction in fuel and the EGR fraction for $1800 \mathrm{rpm}$. The increase of the $\mathrm{CO}_{2}$ mass fraction in fuel decreases indicated mean effective pressure, and the decrease of EGR fraction increases indicated mean effective pressure. It is possible to find that the indicated iso-line of constant means

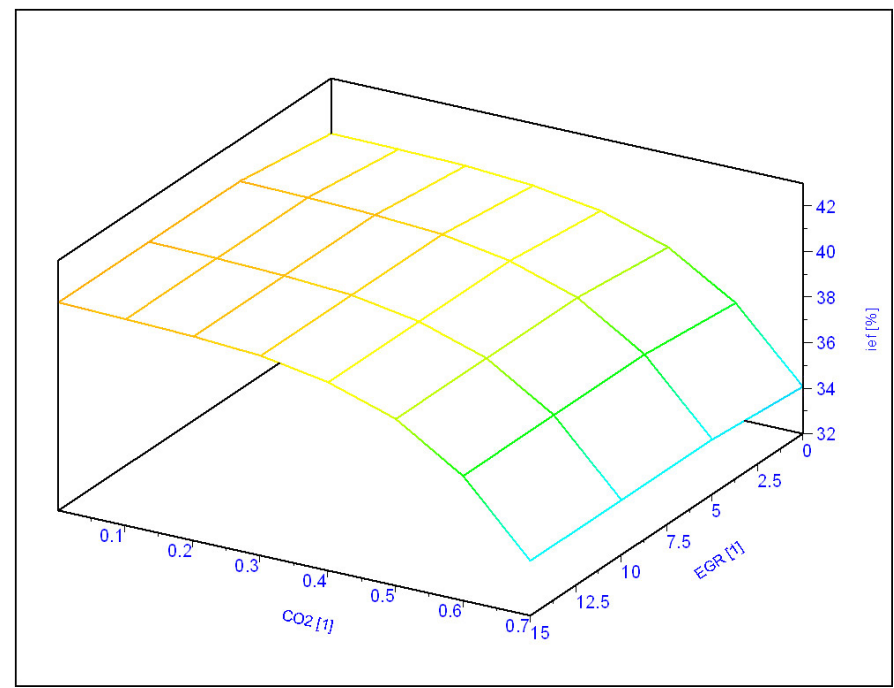

FIGURE 19: Indicated efficiency map for EGR control OBRÁZEK 19: Mapa indikované účinnosti pro rízení pomocí EGR 


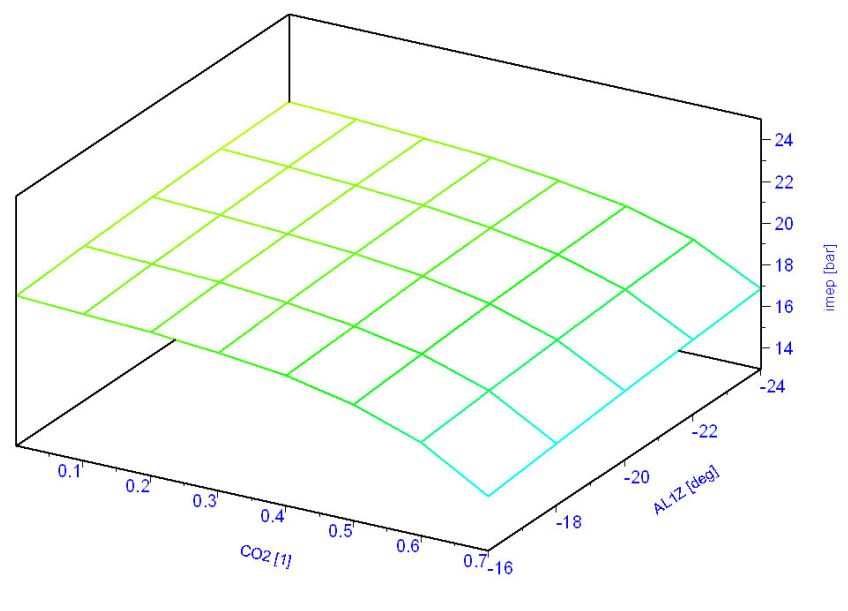

FIGURE 20: Indicated effective mean pressure map for ignition timing control

OBRÁZEK 20: Mapa indikovaného užitečného tlaku pro řízení předstihem zážehu

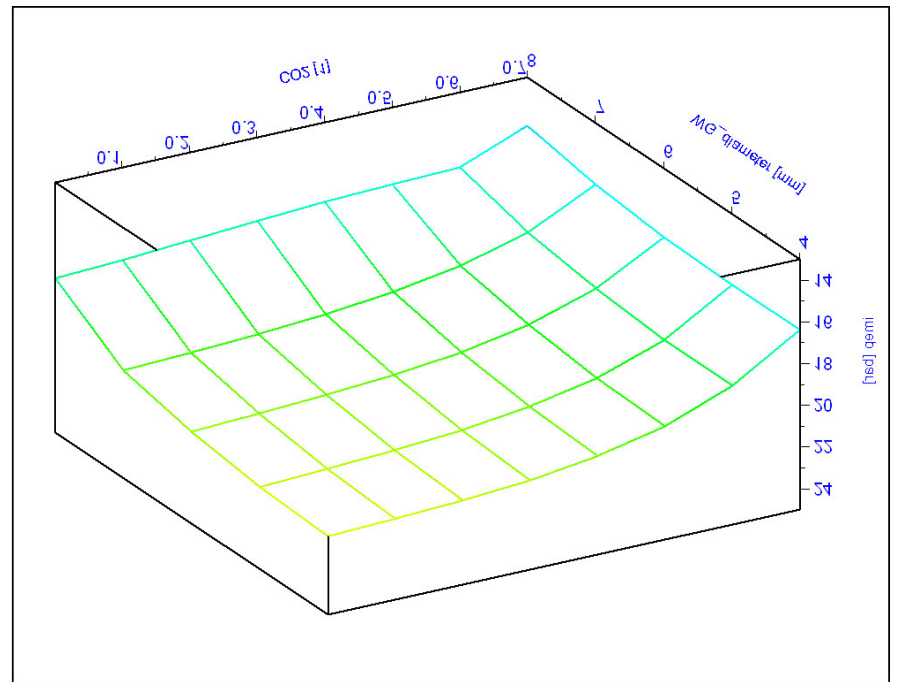

FIGURE 22: Indicated mean effective pressure map for WG control OBRÁZEK 22: Mapa indikovaného užitečného tlaku pro řizení pomocí WG

effective pressure for a wide range of different combinations of EGR fraction and mass fraction of $\mathrm{CO}_{2}$ in fuel.

Figure 19 shows the dependence of indicated efficiency on the $\mathrm{CO}_{2}$ mass fraction in fuel and the EGR fraction for $1800 \mathrm{rpm}$. The increase of the $\mathrm{CO}_{2}$ mass fraction in fuel decreases indicated efficiency. In the region of low EGR rates the indicated efficiency rises with the increased EGR amount. This rather unexpected phenomenon is very interesting and certainly requires the implementation of future studies and further explanation.

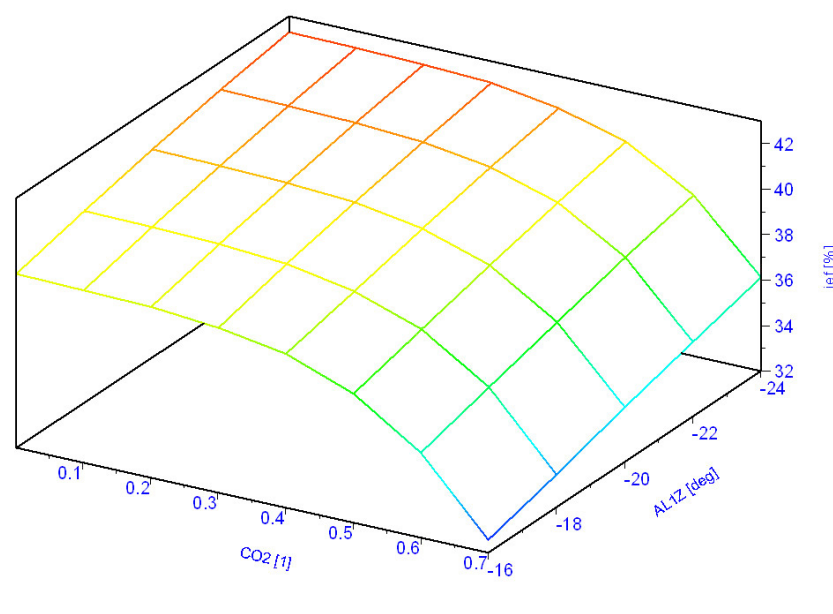

FIGURE 21: Indicated efficiency map for ignition timing control OBRÁZEK 21: Mapa indikované účinnosti pro řízení předstihem zážehu

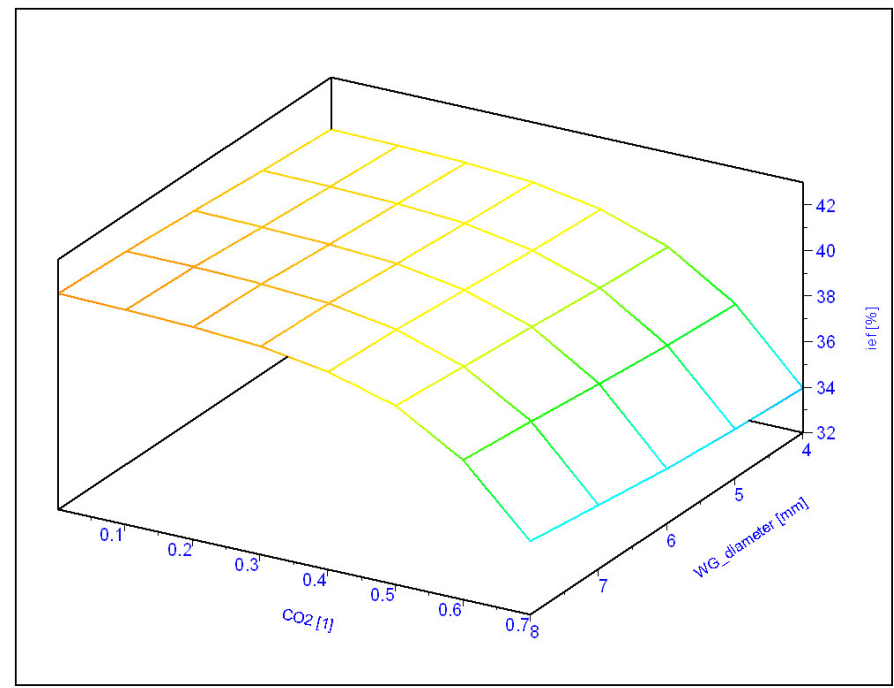

FIGURE 23: Indicated efficiency map for WG control

OBRÁZEK 23: Mapa indikované účinnosti pro řízení pomocí WG

\subsection{IGNITION TIMING CONTROL}

Ignition timing control was simulated with the synchronous change of ignition timing and mass fraction of $\mathrm{C}_{3} \mathrm{H}_{8^{\prime}} \mathrm{H}_{2}$ and $\mathrm{CO}_{2}$ in fuel. The change of ignition timing was modelled by the change of the corresponding parameter in the HR model. The change of mass fraction of additional gases was modelled by the change of fuel definition. Other parameters were not changed intentionally, however some of them (for example boost pressure, etc.), changed, being influenced by the change of ignition timing and mass fraction of addition gases.

Figure 20 shows the dependence of indicated effective mean pressure on the $\mathrm{CO}_{2}$ mass fraction in fuel and ignition timing 
for $1800 \mathrm{rpm}$. The increase of the $\mathrm{CO}_{2}$ mass fraction in fuel decreases indicated mean effective pressure, and the retarded ignition timing increases indicated mean effective pressure. It is possible to find the indicated iso-line of constant mean effective pressure for different combinations of ignition timing and the $\mathrm{CO}_{2}$ mass fraction in fuel, but only within a very limited range of these combinations.

Figure 21 shows the dependence of indicated efficiency on the $\mathrm{CO}_{2}$ mass fraction in fuel and ignition timing for the basic operation regime for $1800 \mathrm{rpm}$. The increase of the $\mathrm{CO}_{2}$ mass fraction in fuel decreases indicated efficiency. The decrease of ignition timing decreases indicated efficiency.

\subsection{BOOST PRESSURE CONTROL}

Boost pressure control was simulated with the synchronous change of VTG rack position (turbine nozzle area) and mass fractions of $\mathrm{C}_{3} \mathrm{H}_{8^{\prime}} \mathrm{H}_{2}$ and $\mathrm{CO}_{2}$ in fuel. The change of VTG rack position was modelled by a change of rack parameter in the turbine definition part of the model. (The VTG rack position 1 represents maximum turbine nozzle area » minimum boost pressure; the VTG rack position 0 represents minimum turbine nozzle area » maximum boost pressure). The change of the mass fraction of additional gases was modelled by the change of fuel definition. Other settings were kept constant.

Figure 22 shows the dependence of indicated mean effective pressure on the $\mathrm{CO}_{2}$ mass fraction in fuel and VTG rack position for $1800 \mathrm{rpm}$. The increase of the $\mathrm{CO}_{2}$ mass fraction in fuel decreases indicated mean effective pressure and the increase of boost pressure increases indicated mean effective pressure. It is possible to find the iso-line of constant indicated mean effective pressure for a wide range of different combinations of VTG rack position and $\mathrm{CO}_{2}$ mass fraction in fuel.

Figure 23 shows the dependence of indicated efficiency on the $\mathrm{CO}_{2}$ mass fraction in fuel and VTG rack position for 1800 $\mathrm{rpm}$. The increase of the $\mathrm{CO}_{2}$ mass fraction in fuel decreases indicated efficiency. The decrease of boost pressure increases indicated efficiency. This indicated efficiency increase is caused by an increase of compressor efficiency (as it is mentioned in the comment to Figure 19). In the case of implementation of boost pressure control the decrease of turbocharger speed also causes movement of compressor operation points towards optimum compressor efficiency which, in turn, positively influences engine efficiency.

\section{CONCLUSIONS}

The computational model developed by the JBRC is dedicated to generating the Heat Release patterns according to the imposed description of operational point and fuel composition. The model is fully furnished with all necessary coefficients, which were calibrated using experimental data acquired on various engines under various operating conditions and with different (methanebased), fuels. The simulation results generated by the most generalized form of the routine were compared to experimental results. The comparison shows a good qualitative agreement, along with certain quantitative differences. It is to be expected that tailoring particular engine design features would further improve the predictive ability.

The most significant impact of fuel composition is on the knock occurrence at full load. The demand for change of ignition timing, which keeps the engine operating just at the knock border (with all other conditions being kept constant), is substantial. Late ignition causes increase of exhaust temperature, increase of turbine power and rise of boost pressure which, if uncontrolled, causes significant increase of engine power. The increase of engine power (and simultaneously the mechanical and thermal load of engine parts), can be easily stopped if necessary or desirable, by some kind of boost control. Since the knockpromoting fuel additives simultaneously accelerate burning velocity during normal (knock-free), combustion, the engine efficiency remains, along the knock-border line, approximately unchanged. When the fuel blend contains a significant amount of knock-suppressing components, a transient from knockdepending control to map-based ignition timing control has to be ensured in order to avoid engine operation with overadvanced ignition.

When normal combustion takes place, the impact of combustion characteristics of various fuels on the engine parameters is less significant but not negligible. Regarding the prospects for obtaining favourable engine efficiency in the area of operational range where no constraints are applied (part load), assessment can start from the most generalized consideration about engine working cycle behaviour. It is generally valid that short combustion duration offers wide manoeuvring space for adjustment of combustion phasing. Once burning velocity decreases (for any reason), the manoeuvring space for ignition timing adjustment becomes narrower, and even when optimum ignition timing is found, engine efficiency (both indicated and effective), cannot achieve the value obtainable by a properly timed short combustion phase. This generalized statement is correspondingly valid for cases when the burning velocity is influenced by fuel composition. In particular, it means that the rising content of components which slow down the burning velocity (for example, carbon dioxide), causes decrease of engine 
efficiency even when ignition timing is optimized for particular fuel composition. An appropriate reaction of ignition timing control to fuel composition enables keeping engine efficiency worsening in an acceptable range. On the other hand, the presence of components which promote burning velocity (hydrogen and high gaseous hydrocarbons), enables improvement of engine efficiency which can be implemented by proper adjustment of ignition timing. Of course, the real operational economy of the gas fuelled vehicle will be (perhaps in a decisive amount), influenced by the cost of fuel itself (which is completely out of reach of thermodynamic-based considerations), and the restriction of vehicle performance associated to on-board energy storage (which will be part of WTW consideration), is probably of greater importance than subtle changes in engine efficiency. Nevertheless, engine efficiency is always one of the main parameters which have to be taken into account during engine optimization.

Raw exhaust gas composition changes slightly with fuel composition variation. The changes show the trends which can be easily derived from mass-balance-based consideration $\left(\mathrm{CO}_{2}\right)$ or from established working cycle behaviour (NO). With the highest probability, exhaust gas after treatment (designed and optimized for use of any methane-based fuel), can ensure acceptable tail pipe emissions.

Certain conclusions are derived from results of systematic model investigation of combined influence of fuel composition with settings of individual control elements.

The effective power is considered to be the most important engine parameter at full load curve. Engine efficiency is of secondary (although not negligible), importance as already mentioned. Then, the conditions are investigated in order to enable the engine to reach the same power when fuelled by various blends as it is reachable when operated with fuel of rated quality (TNG in the present case).

It can be generally concluded that the investigated effects (both of the fuel compositions and control interventions), influence, approximately equally, both the engine power (expressed in terms of imep), and the circumstances which create the constraints (expressed in terms of piston temperature, peak cycle pressure and turbocharger speed). In other words, when power drop, caused by poor fuel, is compensated by an increase of boost pressure or a decrease of EGR rate, the piston temperature and peak pressure reach the same levels as the levels they reach when operated with original fuel and original control settings. Similarly, when thermal and mechanical loads of engine parts are kept at the original level, while engine operated on rather rich fuel (either by increase of EGR rate or by restriction of boost pressure), the engine power remains approximately at its original level. A significant exception from the aforementioned similarity of influences is the turbocharger speed response to the control interventions in the case of presence of $\mathrm{CO}_{2}$ in fuel. Probably due to the slow burning of $\mathrm{CO}_{2}$ - containing fuel and subsequently rising exhaust gas temperature, the turbocharger speed increases steeply under certain operating points and under certain simulated cases, even exceeding the limit.

In the case of necessity for compensation for a power drop, the aforementioned statement is valid, providing that there is certain manoeuvring space. The pessimistic assessment of a possible restoration of the original power during operation with a weak fuel, and when all control elements have been already settled to position engine power to its maximum (typically in the low speed area of full load curve as previously derived from experimental results), is not touched. When fuel, with high mixture CV and high burning velocity, has to be treated, the problem can be expected in the high speed region of full load curve. The full stroke of the boost pressure control actuator can be exhausted. The increase of EGR rate is always possible, but it can cause increased demand for EGR line dimensioning (disadvantageous from cost reason), and/or increased demand for exhaust gas overpressure at the inlet side of EGR line (disadvantageous for thermodynamic reasons).

It can be expected that the control strategy will primarily exploit the restriction of EGR rate for adaptation of the engine to weak fuels, while fuels with high mixture $\mathrm{CV}$ and high burning velocity will be treated by boost pressure control. Ignition timing itself offers only a limited possibility to control engine power. Adjustment of ignition timing will aim either at obtaining optimum combustion phasing or at enhancing the effectiveness of the two remaining control interventions (or will be chosen as an appropriate compromise between both of them).

Finally, it can be concluded that the advanced control system offers appreciable possibilities to adapt the engine for operation with various fuels. On the other hand, it has to be mentioned that this possibility is not unlimited and certain reasonable restrictions have to be implemented on the gas supply side.

\section{ACKNOWLED GMENT}

The results presented in the article have been obtained in the framework of participation of the author's workplace in the Integrated project InGas Integrated Gas Powertrain - Low Emission, $\mathrm{CO}_{2}$ optimized and efficient CNG engines for passenger's cars (PC) and light duty vehicles (LDV) SCS7-GA-2008-218447. 
LIST OF NOTATIONS AND ABBREVIATIONS

$\begin{array}{ll}\text { aTDC } & \text { after top dead centre } \\ \text { BF } & \text { burned fuel fraction } \\ \text { bmep } & \text { brake mean effective pressure } \\ \text { Bsfc } & \text { Brake specific fuel consumption } \\ \text { bshc } & \text { brake specific heat consumption } \\ \text { bTDC } & \text { before top dead centre } \\ \text { CNG } & \text { compressed natural gas } \\ \text { COV } & \text { covariance of indicated mean effective pressure } \\ \text { CV } & \text { calorific value } \\ \text { DSP } & \text { digital signal processor } \\ \text { EGR } & \text { exhaust gas recirculation } \\ \text { HR } & \text { heat release fraction } \\ \text { IMEP } & \text { indicated mean effective pressure } \\ & \text { air excess } \\ \text { LD } & \text { light duty } \\ \text { NDIRA } & \text { non-dispersive infrared analyzer } \\ \text { RGC } & \text { residual gas content } \\ \text { TNG } & \text { transit natural gas } \\ \text { TPA } & \text { three pressure analysis } \\ \text { VTG } & \text { variable turbine geometry } \\ \text { WG } & \text { waste gate } \\ \text { WOT } & \text { wide open throttle }\end{array}$

\section{REFERENCES}

[1] ISO 6973 Natural gas - Calculation of calorific values, density, relative density and Wobbe index from composition

[2] Morel T. \& Goerg K. A. (2005). Use of TPA (Three Pressure Analysis) to Obtain Burn Rates and Trapped Residuals. GT-SUITE Conference - Detroit.

[3] Škarohlíd M. (2010) GTlusr70_dp - Dynamic linked library for GT-POWER version 7.0 [computer program], Prague: Czech Technical University in Prague.

[4] Škarohlíd M. (2010). GTlusr62_dp - Dynamic linked library for GT-POWER version 6.2 [computer program], Prague: Czech Technical University in Prague.

[5] Vávra J. 2004). Influence of Mixture Temperature on Enviromental Properties of Gas Fuelled SI Engine and its Power and Efficiency. (In Czech) Unpublished doctoral dissertation, CTU Prague.

[6] Vávra J. \& Takáts M. (2004). Heat Release Regression Model for Gas Fuelled SI Engines. SAE Paper No. 2004-01-1462

[7] Csallner P., Woschni G. (1982). Zur Vorausberechnung des Brennverlaufes von Ottomotoren bei geänderten Betriebsbedingungen. MTZ 1982, No. 5

[8] Woschni, G. \& Anisits, F. (1974). Experimental Investigation and Mathematical Presentation of Rate of Heat Release in Diesel Engines Dependent Upon Engine Operating Conditions. SAE Paper No. 740086

[9] Škarohlíd M. (2010). Modelling of influence of Biogas Fuel Composition on parameters of automotive engines. SAE Paper No. 2010-01-0542

[10] Škarohlíd M. 2009). New Methods of Determination of Effect Factors for the Cumulative Combustion Rate. KOKA 2009 - XXXX. International scientific conference of the Czech and Slovak Universities, Departments and Institutions Dealing with the Research of Combustion Engines, Nitra 2009, Advances in Automotive Engineering, Volume I, pp. 46-53. ISBN 978-80-552-0255-6

[11] Takáts M. (1997). Měření emisí spalovacích motorů. (In Czech) Czech Technical University in Prague. ISBN 80-01-01632-3"

[12] Klír V. (2010) Description of knock onset in a turbocharged gas engine. MECCA. 8(2), p. 28-34. 